\title{
MEDIDAS ISOTÓPICAS DE CARBONO E OXIGENNIO EM CARBONATOS DO GRUPO BAMBUÍ, NA REGIÃO CENTRO-NORTE DO ESTADO DA BAHIA
}

\author{
JOAQUIM RAUL TORQUATO* e AROLDO MISI**
}

\begin{abstract}
Analyses of 85 carbonate samples of the Bambui Group from the Chapada de Irecê, Bahia, exhibit four distinct ${ }^{13} \mathrm{C}$ and ${ }^{18} \mathrm{O}$ isotopic ratio groupings. Based on these results the following sedimentation model for the Bambuí Group is proposed:

1. A continental environment originating the basal dolomitic limestones and argillaceous dolomites. Isotopic ratios from these rocks fall within ranges considered typical of continental sedimentation: $\delta^{13} \mathrm{C}$ between -2.9 and $-6.4 \%$, and $\delta^{18} \mathrm{O}$ from -5.3 to $-10.7 \%$ (PDB).

2. An alternating continental and restricted marine environment resulting in the deposition of laminated dolomitic limestones with thin interbeds of muddy sediments. $\delta^{13} \mathrm{C}$ ratios of +0.1 to $-4.9 \%$ and a mean value of $-8.2 \pm 0.3 \% \delta^{18} \mathrm{O}$ are compatible with such an environment.

3. A restricted marine environment dominated by sedimentation of the black, fetid limestones of the upper portion of the sequence. Isotopic ratios for ${ }^{13} \mathrm{C}$ are all over $-1.8 \%$, up to about $+7.5 \%$, and ${ }^{18} \mathrm{O}$ ratios vary from -4.9 to $-10.0 \%$. A number of light-grey sileceous dolomites is interbeded with the lowermost black limestones of this sequence. Isotopic data for these rocks show a narrow range for $\delta^{13} \mathrm{C}$ values $(-0.5$ to $1.0 \%)$ and a broader variation for $\delta^{18} \mathrm{O}$ ratios $(0.0$ to $-8.3 \%$ o $)$. This latter may be interpreted as indicative of intense evaporation during deposition of the dolomitic facies.
\end{abstract}

INTRODUÇÃo O registro bibliográfico sobre o Grupo Bambuí no Brasil é relativamente grande, no que pese o fato de que muitas dúvidas ainda persistam, com respeito à sua estratigrafia e ao seu ambiente deposicional. A recente descoberta de uma jazida de sulfetos de $\mathrm{Pb}-\mathrm{Zn}-\mathrm{Cu}$ em dolomitos recifais na região de Morro Agudo, Minas Gerais, contribuiu para aumentar o interesse das empresas governamentais e privadas pelo potencial metalogenético que pode estar representado nas sequiências carbonáticas dessa unidade.

As fácies representativas do Grupo Bambuí (originalmente assim definido em Minas Gerais) encontram unidades correlacionáveis numa grande extensão do território brasileiro; compreendem uma área de mais de $350000 \mathrm{~km}^{2}$, ocorrendo principalmente nos Estados de Minas Gerais, Bahia e Goiás. De um modo geral, tem sido admitida uma origem marinha para essas fácies; no entanto, interpretações mais detalhadas de subambientes são escassas na literatura, uma vez que têm faltado elementos suficientes de análise.

Com base em análises isotópicas para carbono e oxigênio realizadas em 85 amostras de diferentes fácies carbonáticas da borda leste da chapada de Irecê, Bahia, pretende-se demonstrar que a região passou por um processo evolutivo contínuo, próprio de regiões plataformais, mostrando um período talassocrático completo. Os ambientes sugeridos pelos valores isotópicos são compatíveis com os dados de campo obtidos no mapeamento geológico de detalhe, previamente realizado na região.

Esse trabalho constitui parte de um projeto mais amplo: Projeto Chumbo-Zinco no Bambuí, iniciado em 1971, com apoio financeiro do BNDE-FUNTEG e posteriormente do FINEP-Ministério do Planejamento e executado no âmbito do Programa de Pesquisa e Pós-Graduação em Geofisica da Universidade Federal da Bahia. O Projeto representa

* Instituto de Física, da Universidade Federal da Bahia, Salvador

** Instituto de Geociências da Universidade Federal da Bahia, Salvador 
uma área de integração entre o referido Programa e o Setor de Geologia Econômica do Departamento de Geologia e Geofisica Aplicada do Instituto de Geociências.

Técnicas analiticas As técnicas analíticas empregadas são as usuais para o Laboratório de Geofisica Nuclear do Instituto de Física/PPPG, UFBa, as quais são resumidas a seguir.

a) Ataque das amostras, pulverizadas a 200 mesh, com ácido fosfórico a $95 \%$ preparado segundo as técnicas descritas por McGrea (1950), com homogeneização isotópica a $25^{\circ} \mathrm{C}$ durante 24 horas.

b) Análise isotópica do $\mathrm{CO}_{2}$ em espectrômetro de massa NUGLIDE, com 6 pol de raio de curvatura e $60^{\circ}$ de deflexão do tipo 6-60 - RMS.

Os valores $\delta^{13} \mathrm{C}$ e $\delta^{18} \mathrm{O}$ foram calculados em desvios por mil, relativamente a um padrão interno (padrão Bahia) e corrigidos para valores $\mathrm{PDB}_{1}$ (Chicago, Belemnite standard). As fórmulas empregadas, foram as de Craig (1953 e 1957)

e

$$
\begin{aligned}
& \delta^{13} \mathrm{G}=\frac{{ }^{13} \mathrm{G} /{ }^{12} \mathrm{C} \text { Amostra }{ }^{-13} \mathrm{C} /{ }^{12} \mathrm{G} \text { padrão }}{{ }^{13} \mathrm{C} /{ }^{12} \mathrm{G} \text { padrão }} \times 1000 \\
& \delta^{18} \mathrm{O}=\frac{{ }^{18} \mathrm{O} /{ }^{16} \mathrm{O} \text { Amostra }{ }^{-18} \mathrm{O} /{ }^{16} \mathrm{O} \text { padrão }}{{ }^{18} \mathrm{O} /{ }^{16} \mathrm{O} \text { padrão }} \times 1000 .
\end{aligned}
$$

O material analisado foi coletado em afloramentos superficiais, utilizando-se sempre amostras não-alteradas.

GEOLOGIA A seqüência de rochas carbonáticas que ocorrem na região centro-norte do Estado da Bahia tem sido correlacionada às unidades reconhecidas em Minas Gerais e Goiás como pertencentes ao Grupo Bambuí, de idade pré-cambriana superior. Datações em folhelhos do Grupo Bambuí pelo método $\mathrm{Rb} / \mathrm{Sr}$, realizadas por Amaral e Kawashita (1967) revelaram idades de $600 \pm 50$ milhões de anos. Mais recentemente, Cloud e Dardenne (1973), através do estudo de estruturas estromatolíticas algais do tipo Conophyton encontradas na região de Vazante (Minas Gerais) sugeriram idades entre 950 e 1350 milhões de anos, para a sedimentação do Grupo Bambuí.

$\mathrm{Na}$ região centro-oeste do Estado da Bahia, o Grupo Bambuí repousa discordantemente sobre quartzitos do Grupo Chapada Diamantina, dobrados em amplos anticlinais e sinclinais assimétricos.

A área objeto do presente trabalho, localizada na borda leste da Chapada de Irecê (Fig. 1), foi mapeada em detalhe por Misi (1973), que propôs a coluna estratigráfica mostrada na Fig. 2. O Grupo Bambuí, nessa região, comporta uma seqüência carbonática e uma seqüência principalmente terrígena, na base (Formação Bebedouro) constituída por metargilitos e metagrauvacas conglomeráticas, com freqüentes intercalações de sílex.

As unidades carbonáticas constituem objeto das análises isotópicas realizadas para esse trabalho. As seguintes unidades a seguir foram reconhecidas, a partir do topo.

Unidade $A$ Constitui a fácies dominante, caracterizada principalmente pela ocorrência de calcários micríticos pretos, aos quais se associam alguns horizontes com abundantes oólitos e intraclastos. Uma característica marcante desses calcários é o fato de serem fortemente odorosos (fétidos), sobretudo quando quebrados com o martelo. Com relativa freqüência observa-se também a ocorrência de níveis de brecha intraformacional, com fragmentos angulares e de contornos nítidos de calcário preto, numa matriz fina, de cal- 


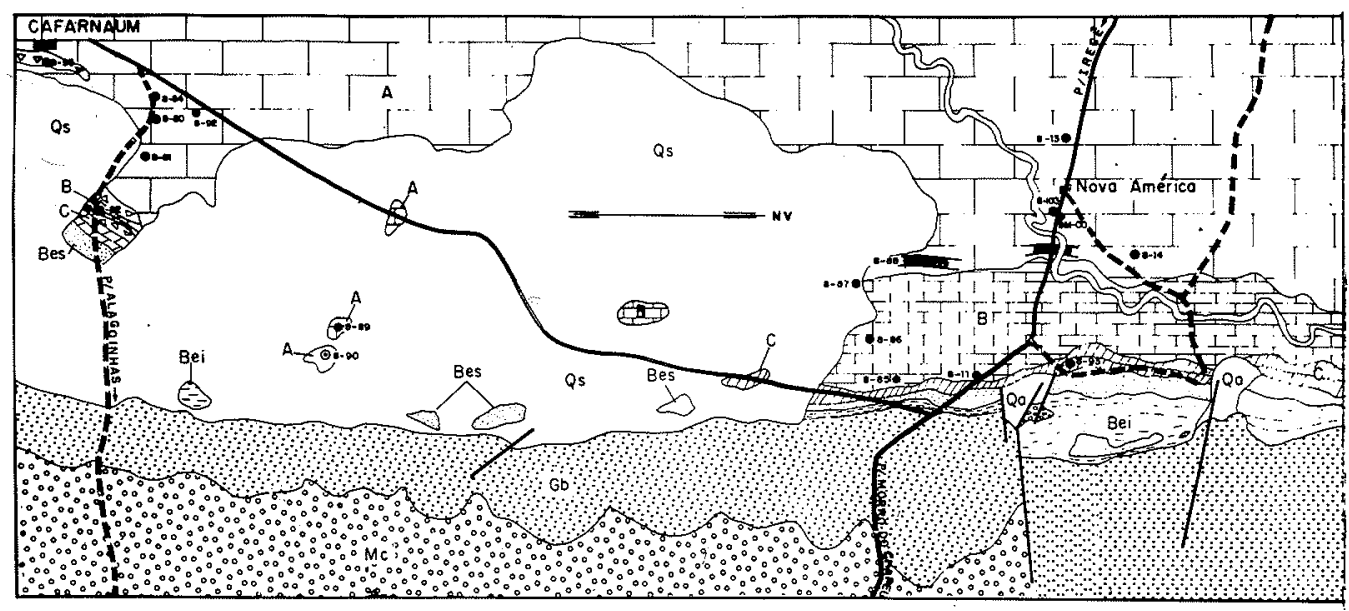

Qo Aluviōes

Qs Coberturo

GRUPO BAMBUÍ

UNIDADE A (A)

1 Calcarios ooliticos e calcórios micríticos pretos. Dolomitos a dolomitos oolíticos, UIDADE

Calcários dolomíticos laninados. Niveis

de brecha intratormacional

UNIDADE $O$ (c)

Dolomitos vermelhos, argilosos

UNIDADE D (Formaçōo Bebedouro)

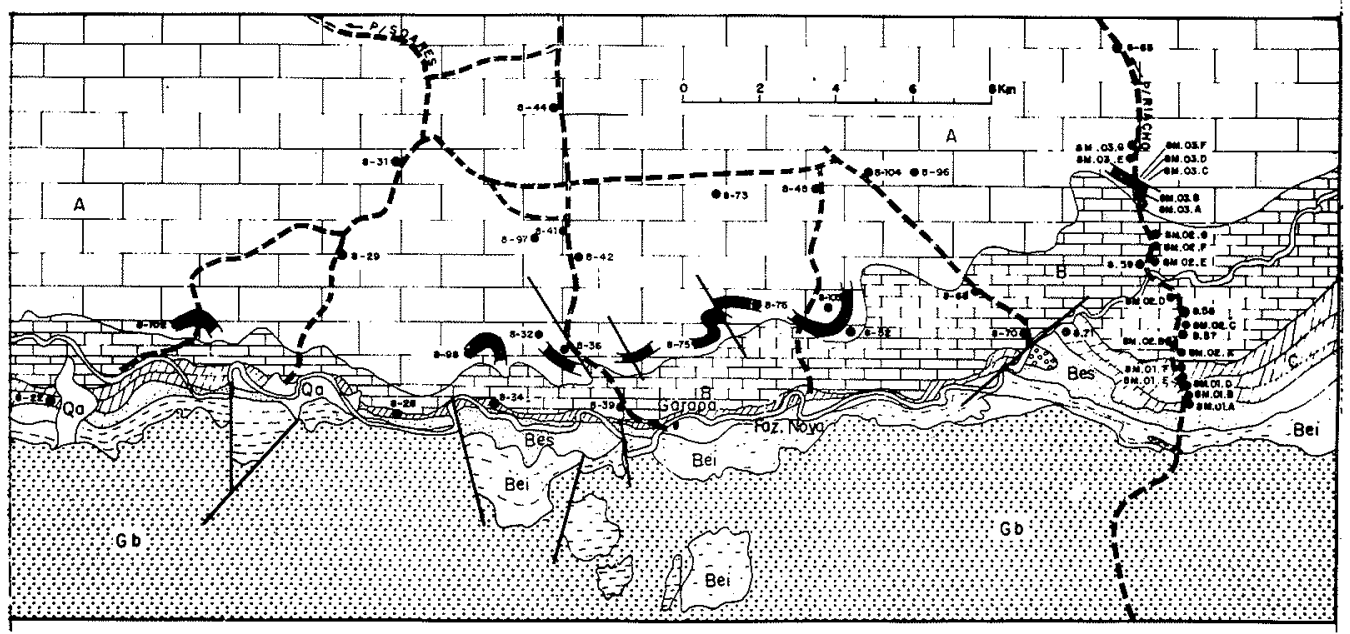

Quartzitos feldspáticos (Bes)

$=$ Metassiltitos e metargilitos, metagrauvaco

GRUPO CHAPADA DIAMANTINA

FORMAÇÁO GUARIBA (GD)

Quartzitos e metargilitos

FORMAÇÃO MORRO DO CHAPÉU (MC)

$\because 0 \%$ Quartzitos conglomeráticos

Figura 1 - Mapa geológico da borda leste da Chapada de Irecê com indicação dos pontos amostrados para medidas isotópicas 


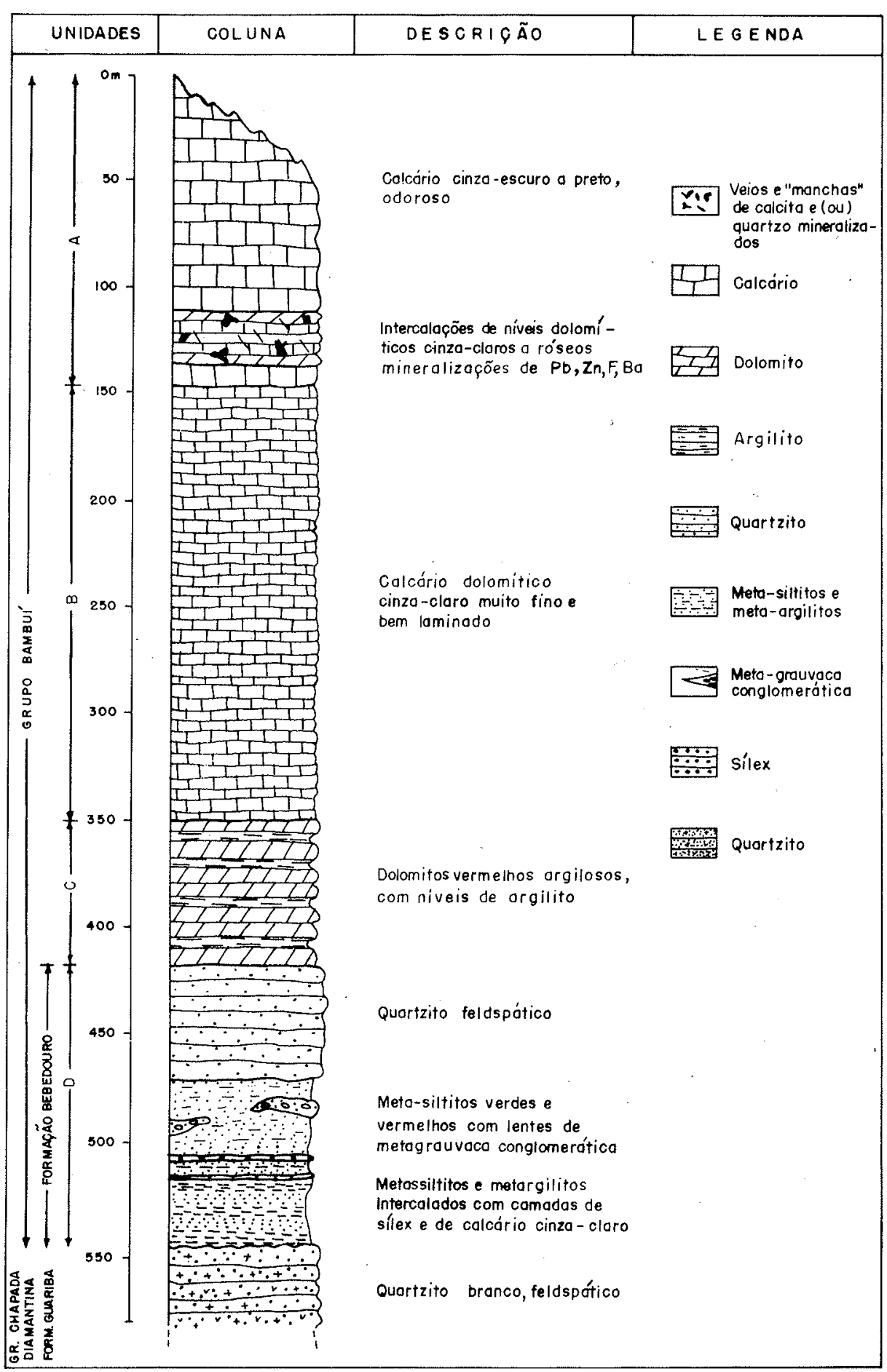

Figura 2 - Coluna estratigráfica do Grupo Bambuí na borda leste da Chapada de Irecê 
cário cinza-azulado. Os níveis de brecha intraformacional ocorrem com maior freqüência na parte sul da área, onde são observados também intensos dobramentos de escorregamento.

Próximo à base dessa unidade, ocorrem várias intercalações de dolomitos, com 1 a $2 \mathrm{~m}$ de espessura, contínuos ao longo de vários quilômetros e num intervalo estratigráfico de mais de $20 \mathrm{~m}$. São dolomicritos e dolomitos oolíticos, onde são frequientes as concreções de calcedônia, podendo ser observados, também, grãos de plagioclásio com crescimento autigênico.

Os horizontes dolomíticos e os calcários pretos adjacentes, quando atrávessados por veios de quartzo ou de calcita, mostram-se quase sempre mineralizados com fluorita e eventualmente com galena, esfalerita e barita. A fluorita ocorre também em pequenos núcleos de calcita, disseminada nos dolomitos oolíticos.

Estruturas estromatolíticas algais foram observadas em algumas localidades, associadas aos carbonatos dessa unidade.

Unidade $B$ Garacteriza-se pela presença de calcários laminados, de coloração cinza-clara, freqüentemente dolomíticos. São visíveis ao microscópio finos leitos de material síltico-argiloso, de coloração avermelhada, razão principal do caráter laminado dessa unidade. Por vezes, principalmente em outros locais fora da área estudada, os horizontes síltico-argilosos apresentam espessuras centimétricas, como por exemplo, na região de Barra do Mendes, na borda oeste do sinclinório de Irecê.

São comuns ocorrências de intercalações centimétricas, e às vezes métricas, de calcários cinza-azulados a pretos, que ocorrem com maior freqüência no topo, onde se nota uma passagem gradativa para a unidade $\mathrm{A}$. Na base, ocorrem também intercalações de calcário cinza-azulado, com níveis argilosos vermelhos.

Unidade $C$ Sobrepõe-se em contato normal aos quartzitos da Formação Bebedouro; no topo, passa gradativamente para calcários cinza-claros e laminados, da unidade B.

Essa unidade é constituída por calcários dolomíticos e dolomitos, vermelhos, com intercalações milimétricas a centimétricas de metargilitos. Os cristais de carbonato mostram íntima associação com material argiloso. Verifica-se também a presença de cristais euedrais de quartzo constituindo menos de $5 \%$ da rocha, bem como raros grãos de plagioclásios. Na localidade de Garapa, foram observadas gretas de contração, preenchidas por quartzo.

$\mathrm{Na}$ área estudada, esta unidade mostra uma notável persistência lateral, ao longo de toda extensão, o mesmo não acontecendo na borda oeste, onde a sua ocorrência é lenticular e descontínua; em mais de uma localidade, verificou-se a ocorrência de estruturas estromatolíticas algais, associadas aos dolomitos.

Resultados analíticos e discussões Medidas de $\delta^{13} \mathrm{G}$ e de $\delta^{18} \mathrm{O}$ foram efetuadas em 85 amostras das diversas fácies carbonáticas, assim distribuídas:

- calcários micríticos pretos, da unidade $\mathrm{A}$,

- dolomitos e dolomitos oolíticos silicosos da base da unidade A,

- calcários e calcários dolomíticos laminados, da unidade B,

- calcários dolomíticos e dolomitos vermelhos e argilosos da unidade $\mathrm{C}$,
28 amostras;

30 amostras;

15 amostras;

12 amostras.

Os resultados analíticos estão nas Tabs. I, II, III e IV. A Fig. 3 traz a distribuição dos resultados num gráfico do tipo $\delta^{18} \mathrm{O}$ versus $\delta^{13} \mathrm{C}$. 
Tabela 1 - Unidade A

\begin{tabular}{|c|c|c|c|}
\hline $\begin{array}{l}\text { No LABORA } \\
\text { - TÓRIO }\end{array}$ & NOAMOSTRA & $\delta_{\% 0}^{13} C_{(P D B)}$ & $\delta_{\%}^{18}{ }^{18}(\mathrm{POB})$ \\
\hline$B A X-339$ & $8-13$ & $+0,9$ & $-6,1$ \\
\hline$B A X-336$ & $8-29$ & $+6,1$ & $-6,1$ \\
\hline$B A X-319$ & $8-31$ & $-1,0$ & $-8,8$ \\
\hline$B A X-338$ & $8-36-B$ & $+0,6$ & $-5,0$ \\
\hline$B A X-345$ & $8-41-A$ & $-4,6$ & $-9,8$ \\
\hline$B A X-324$ & $8-42$ & $+6,6$ & $-6,7$ \\
\hline$B A X-315$ & $8-44$ & $+0,4$ & $-6,7$ \\
\hline$B A X-325$ & $8-48-A$ & $+1,5$ & $-5,4$ \\
\hline$B A X-326$ & $8-52$ & $-1,8$ & -7.3 \\
\hline$B A X-423$ & $8-65$ & $+6,9$ & $-6,6$ \\
\hline$B A X-307$ & $8-73$ & $+4,9$ & $-5,8$ \\
\hline$B A X-317$ & $8-80$ & 0,0 & $-5,3$ \\
\hline$B A X-349$ & $-8-81-A$ & $-0,9$ & $-6,0$ \\
\hline$B A X-374$ & $8-81-D$ & $+1,0$ & $-8,1$ \\
\hline$B A X-347$ & $B-84-A$ & $-0,6$ & $-5,1$ \\
\hline$B A X-348$ & $8-84-A^{\prime}$ & $-0,8$ & $-4,9$ \\
\hline$B A X-424$ & $8-87-A$ & $-0,3$ & $-5,0$ \\
\hline$B A X-426$ & $8-89$ & $-1,6$ & $-7,7$ \\
\hline$B A X-368$ & $B-90-A$ & $-1,2$ & $-7,1$ \\
\hline BAX -329 & $8-95$ & $-1,4$ & $-5,8$ \\
\hline$B A X-314$ & $8-96$ & $+4,4$ & $-5,6$ \\
\hline$B A X-361$ & $B-97-B$ & $-5,0$ & $-8,4$ \\
\hline$B A X-521$ & $8-103-M$ & $-0,9$ & $-6,7$ \\
\hline$B A X-442$ & $8-105-C$ & $-1,0$ & $-7,6$ \\
\hline$B A X-438$ & $8 M-03-A$ & $-0,9$ & $-8,3$ \\
\hline$B A X-441$ & $8 M-03-B$ & $-1,0$ & $-7,2$ \\
\hline$B A X-421$ & $8 M-03-E$ & $-0,9$ & $-10,0$ \\
\hline BAX -419 & $8 M-03-6$ & $+7,5$ & $-6,1$ \\
\hline
\end{tabular}

Tabela III - Unidade B

\begin{tabular}{|c|c|c|c|}
\hline $\begin{array}{l}\text { NO- LABORA } \\
\text { - TÓRIO }\end{array}$ & $N^{\circ}$ AMOSTRA & $\left.\int_{\%}{ }^{13} C_{(P D B}\right)$ & $\delta_{(\mathrm{PDB})}$ \\
\hline $8 A X-337$ & $8-11$ & $-4,9$ & $-8,9$ \\
\hline$B A X-350$ & $8-39$ & $+0,1$ & $-8,3$ \\
\hline BAX -304 & $8-57$ & $-2,7$ & $-9,2$ \\
\hline$B A X-305$ & $8-58$ & $-0,3$ & $-8,0$ \\
\hline$B A X-375$ & $8-59-8$ & $-1,5$ & $-8,2$ \\
\hline$B A X-342$ & $8-68$ & $-1,0$ & $-6,5$ \\
\hline$B A X-318$ & $8-70$ & -0.7 & $-8,1$ \\
\hline$B A X-320$ & $B-82-A$ & $-2,3$ & $-9,0$ \\
\hline$B A X-413$ & $8 M-02-A$ & $-3,2$ & $-9,6$ \\
\hline$B A X-411$ & $8 M-02-8$ & $-0,1$ & $-9 ; 8$ \\
\hline $8 A X-409$ & $8 M-02 C$ & 0,0 & $-7,9$ \\
\hline$B A X-418$ & $8 M-02-D$ & $-1,3$ & $-8,2$ \\
\hline$B A X-410$ & $8 M-O 2-E$ & $-1,6$ & $-8,3$ \\
\hline$B A X-412$ & $8 M-02-F$ & $-2,1$ & $-8,1$ \\
\hline$B A X-416$ & $8 M-02-G$ & $-2,1$ & $-8,6$ \\
\hline
\end{tabular}

Tabela II - Base da unidade A

\begin{tabular}{|c|c|c|c|}
\hline $\begin{array}{l}\text { NO LABORA } \\
\text { - TÓRIO }\end{array}$ & NAMOSTRA & $\delta_{13} C_{(P D B)}$ & $\delta_{\% \circ} 18$ (PDB) \\
\hline$B A X-316$ & $8-32$ & $+0,3$ & $-3,5$ \\
\hline$B A X-343$ & $8-32-c$ & $+0,3$ & $-3,8$ \\
\hline$B A X-425$ & $8-74$ & $+5,0$ & $-3,8$ \\
\hline$B A X-327$ & $8-75-B$ & $-0,6$ & $-4,3$ \\
\hline BAX - 346 & $8-85$ & $-0,5$ & $-6,3$ \\
\hline$B A X-378$ & $8-86$ & $-1,9$ & $-5,8$ \\
\hline$B A X-371$ & $8-88-A$ & $-0,6$ & -1.1 \\
\hline$B A X-373$ & $8-88-8$ & $+0,2$ & -0.4 \\
\hline$B A X-323$ & $8-90-8$ & $-1,6$ & $-7,9$ \\
\hline$B A X-306$ & $8-92$ & $+0,1$ & $-3,4$ \\
\hline$B A X-328$ & $8-97-A$ & $-4,6$ & $-10,3$ \\
\hline$B A X-430$ & $8-98$ & $-0,5$ & $-3,7$ \\
\hline$B A X-370$ & $8-102$ & $+0,1$ & $-2,6$ \\
\hline$B A X-511$ & $8-103-A$ & $+0,6$ & $-1,7$ \\
\hline$B A X-535$ & $8-103-B$ & $-4,3$ & $-3,0$ \\
\hline$B A X-517$ & $8-103-0$ & $+0,8$ & 0,0 \\
\hline$B A X-513$ & $8-103-E$ & $-0,4$ & $-1,4$ \\
\hline$B A X-514$ & $8-103-F$ & $+0,5$ & $-0,9$ \\
\hline$B A X-369$ & $8-103-6$ & $+0,1$ & $-2,0$ \\
\hline$B A X-515$ & $8-103-H$ & $+0,1$ & $-1,0$ \\
\hline$B A X-519$ & $8-103-I$ & $-0,6$ & $-0,6$ \\
\hline$B A X-518$ & $8-103-J$ & $-1,2$ & $-2,0$ \\
\hline$B A X-520$ & $8-103-K$ & $-0,8$ & $-2,2$ \\
\hline BAX -522 & $8-103-L$ & $-0,7$ & $-2,3$ \\
\hline$B A X-377$ & $8-104$ & $-1,5$ & $-5,0$ \\
\hline$B A X-308$ & $8-105-A$ & $-1,7$ & $-6,8$ \\
\hline$B A X-415$ & $8 M-00$ & $-0,7$ & $-7,4$ \\
\hline$B A X-440$ & $8 M-03-C$ & $-1,3$ & $-1,1$ \\
\hline$B A X-420$ & $8 M-03-0$ & $-1,0$ & $-6,3$ \\
\hline$B A X-417$ & $8 M-03-F$ & $-0,2$ & $-8,3$ \\
\hline
\end{tabular}

Tabela IV - Unidade G

\begin{tabular}{|c|c|c|c|}
\hline $\begin{array}{l}\text { N-LABORA } \\
\text { - TÓRIO }\end{array}$ & NOAMOSTRA & ${ }_{\%}^{\delta 13} C_{(P D B}$ & ${ }_{\%}^{\delta 18} q_{P D B}$ \\
\hline$B A X-321$ & $8-14$ & $-5,4$ & $-9,5$ \\
\hline$B A X-340$ & $8-22$ & $-5,6$ & $-9,5$ \\
\hline$B A X-344$ & $8-28-8$ & $-2,9$ & $-5,3$ \\
\hline$B A X-313$ & $8-34$ & $-5,5$ & $-9,3$ \\
\hline$B A X-376$ & $8-71$ & $-4,6$ & $-7,7$ \\
\hline$B A X-617$ & $8-93-0$ & $-6,1$ & $-9,9$ \\
\hline$B A X-621$ & $8-93-D$ & $-6,0$ & $-9,6$ \\
\hline$B A X-414$ & $B M-01-A$ & $-4,3$ & $-8,0$ \\
\hline$B A X-439$ & $B M-01-B$ & -5.0 & $-10,0$ \\
\hline$B A X-622$ & $8 M-01-D$ & $-4,6$ & $-7,6$ \\
\hline $8 A X-620$ & $8 M-01-E$ & $-4,4$ & $-7,6$ \\
\hline$B A X-616$ & $B M-0 i-F$ & $-6,4$ & $-10,7$ \\
\hline
\end{tabular}




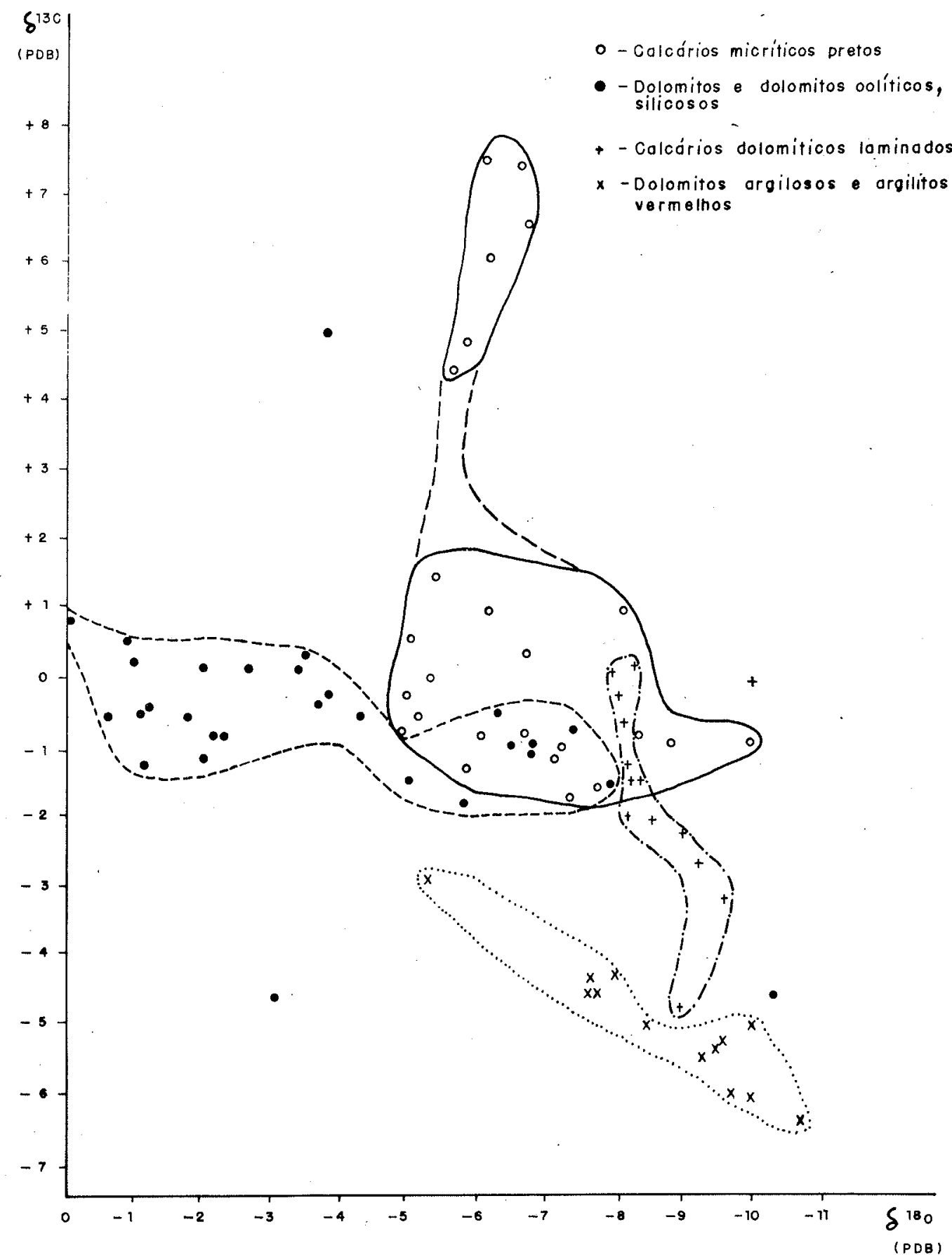

Figura 3 - Relação entre as razões isotópicas de carbono e oxigênio de amostras carbonáticas da Chapada de Irecê 
1) Calcários micríticos pretos Os resultados analíticos das amostras desta unidade mostram uma larga variação de $\delta^{13} \mathrm{C}$, de $+7,5 \mathrm{a}-1,8 \%$ e uma faixa mais estreita de valores $\delta^{18} \mathrm{O}$, de $-4,9$ a $-10,0 \%$.

As análises de $\delta^{13} \mathrm{C}$ mostram todas, sem exceção, valores maiores que $-1,8 \%$. Deve-se salientar a presença de seis amostras com valores muito altos em $\delta^{13} \mathrm{C}$, evidenciando a presença de carbonos pesados. Essas amostras localizam-se na região noroeste da área (Fig. 1), ao longo de um nível com abundantes oólitos.

Os valores obtidos indicam, para a maioria dos autores, um ambiente marinho. Para Weber et al. (1964), os valores compreendidos entre $+1,5$ e $-1,8 \%$ poderiam ser indicativos também de condições de restrição local das águas.

Quanto aos valores muito altos das seis amostras mencionadas, indicando enriquecimento em $\delta^{13} \mathrm{C}$, embora sejam escassos na literatura, Oana e Deevey (1960), Galimov e Girin (1968), Fritz (1969) e Fritz et al. (1971) dedicaram-se ao problema procurando várias explicações. Uma das possíveis seria de natureza biológica: em ambientes com abundante matéria orgânica, onde sejam baixos os valores de $\mathrm{SO}_{4}^{--}$, é bem conhecida a reação que produz metano a partir da degradação bacteriológica da matéria orgânica:

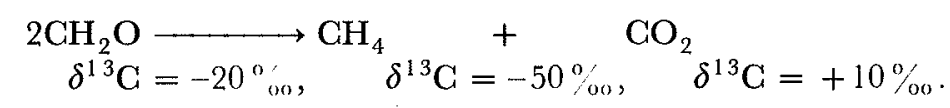

A composição isotópica do metano e do dióxido de carbono produzidos dependeria, acima de tudo, da distribuição dos isótopos de carbono dentro da matéria orgânica (Fritz et al., 1971). Galimov (1969) demonstrou também que o equilíbrio isotópico entre os dois gases só pode ser mantido, em ambiente sedimentar, se o processo de trocas for determinado por bactérias.

No caso em questão, o caráter fortemente odoroso (fétido) das amostras dessa unidade faciológica sugere uma importante contribuição orgânica na sua formação. Por outro lado, considerando a faixa de valores de $\delta^{13} \mathrm{C}$ pesados obtida, $(+4,4 \mathrm{a}+7,5 \%$ ), duas explicações poderiam ser admitidas para o fato de não terem sido atingidos valores mais altos $\left(\delta^{13} \mathrm{C}=+10 \%\right)$, como seria de esperar supondo-se a reação acima referida como válida:

1. A reação não se processou completamente, talvez devido à passagem para um ambiente de mar aberto (muito $\mathrm{SO}_{4}^{--}$)

2. Houve remoção de $\delta^{13} \mathrm{C}$ após a sedimentação do carbonato, provavelmente através de águas meteóricas, conforme o processo preconizado por Land e Epstein (1970).

Pelas razões expostas a seguir, não parece ter havido alteração meteórica muito acentuada, motivo pelo qual se pode admitir a primeira hipótese como a mais válida.

No que se refere à interpretação dos valores de $\delta^{18} \mathrm{O}$, o problema é maior, uma vez que, pelo fato de se tratarem de carbonatos antigos (pré-cambrianos), faltam termos comparativos com valores atuais. Dispõe-se apenas dos dados médios propostos por Keith e Weber (1964) e por Schidlowski et al. (1975); ambos os autores admitem um decréscimo nos valores de $\delta^{18} \mathrm{O}$ ao longo do tempo geológico e aceitam que, para o Pré-cambriano superior, este valor seria em torno de $-11 \pm 1 \%$.

Os valores de $\delta^{18} \mathrm{O}$ das amostras analisadas, podem ser divididos em dois grupos distintos, para efeitos de interpretação:

1. Amostras com $\delta^{13} \mathrm{C}$ pesados, que apresentam um valor médio de $\delta^{18} \mathrm{O}$ em torno de $-6,2 \pm 0,5 \%$

2. Amostras com $\delta^{13} \mathrm{C}$ normais, apresentando uma faixa de variação maior dos valores de $\delta^{18} \mathrm{O}$, entre $-4,9$ e $-10,0 \%$. 
No primeiro grupo, onde o valor médio de $\delta^{18} \mathrm{O}$ é muito inferior ao esperado $\left(\delta^{18} \mathrm{O}=-11 \%\right)$, pode-se admitir que os valores obtidos representam a composição isotópica da água do mar no momento da deposição do carbonato. A grande homogeneidade dos valores e a relação direta com os valores mais altos de $\delta^{13} \mathrm{C}$, sugerem que não houve influência considerável de alteração meteórica, no caso em questão.

O segundo grupo de valores poderia significar o resultado de fracionamento, por evaporação preferencial, de ${ }^{18} \mathrm{O}$.

Dessa forma, o processo de sedimentação poderia ser admissível em um ambiente marinho restrito, com entradas irregulares da água do mar, uma vez que as amostras coletadas abrangem quase toda a área estudada.

2) Dolomitos e dolomitos oolíticos, silicosos Diferentemente dos calcários pretos nos quais se intercalam, apresentam uma faixa pequena de variação de $\delta^{13} \mathrm{G}$ com um valor médio de $-0,5 \pm 1,0 \%$. Esse valor, constante nas 30 amostras analisadas, refere-se provavelmente ao valor da razão ${ }^{13} \mathrm{C} /{ }^{12} \mathrm{C}$ por ocasião da sua formação. Por outro lado, a grande faixa de variação de $\delta^{18} \mathrm{O}(0,0 \mathrm{a}-8,3 \%)$ pode ser indicativa de um processo de evaporação intensa em ambiente marinho restrito.

Esses resultados constituem fator importante e decisivo para admitir-se o caráter primário desses dolomitos, conforme proposto por Misi (1973), com base nas relações de campo. De cutra forma, durante uma dolomitização secundária, deveria ocorrer uma homogeneização isotópica conforme os modelos propostos por Degens e Epstein (1964) e por Weber (1964). Para esses autores os dolomitos de origem secundária devem apresentar valores de $\delta^{18} \mathrm{O}$ semelhantes ou ligeiramente superiores aos calcários que lhe deram origem.

As amostras de número de laboratório BAX 328, BAX 425 e BAX 535 não foram tratadas interpretativamente por se encontrarem totalmente fora do padrão apresentado pelas restantes. Nos três casos, as análises foram repetidas e os valores mantiveram-se dentro do erro experimental.

3) Calcários dolomíticos cinza-claros, laminados Conforme foi descrito, os calcários dolomíticos da unidade B são laminados, com intercalações mais ou menos regulares de material síltico-argiloso. Tal alternância pode explicar os valores de $\delta^{18} \mathrm{O}$ encontrados e ajudar a interpretação isotópica.

A variação em $\delta^{13} \mathrm{G}$ é de $+0,1$ a $-4,9 \%$. Esses valores, de acordo com as interpretações de Keith e Weber (1964), sugerem que as amostras analisadas se situam num domínio misto de deposição, entre águas doces e águas marinhas (o limite adotado por Keith e Weber, através do estudo de 500 amostras, foi de $\delta^{13} \mathrm{C}=-2 \%$ ). Usando o modelo de Weber et al. (1964), que admite como limite entre o ambiente marinho franco e o marinho restrito, o valor de $\delta^{13} \mathrm{C}=+1 \%$, verifica-se que os resultados obtidos refletem variações de ambiente desde continental puro até marinho restrito (de baixa energia), nunca alcançando valores francamente marinhos.

Os valores obtidos para $\delta^{18} \mathrm{O}$ são compativeis com os ambientes indicados. Assim, as amostras de caráter marinho restrito apresentam um valor médio de $\delta^{18} \mathrm{O}$ de $-8,2 \pm$ $\pm 0,3 \%$, enquanto que as de ambiente continental, como seria de se esperar, apresentam valores mais negativos $\left(\delta^{18} \mathrm{O}=-9,3 \pm 0,3 \%\right.$ ). Embora todas as análises tenham sido efetuadas em rochas carbonáticas, as variações encontradas refletem perfeitamente a grande diferença nas condições de sedimentação.

4) Calcários dolomíticos e dolomitos vermelhos, argilosos As rochas da unidade $\mathrm{C}$, representadas por calcários dolomíticos e dolomitos vermelhos argilosos, apresentam-se com padrão 
semelhante ao dos dolomitos silicosos da unidade A, embora com valores distintos. Seus valores extremos para $\delta^{13} \mathrm{C}$ são $-2,9 \mathrm{e}-6,4 \%$ e para $\delta^{18} \mathrm{O}$ são $-5,3 \mathrm{e}-10,7^{\circ} \%$. As amostras encontram-se, entre esses valores, com uma distribuição bastante homogênea.

De acordo com os trabalhos referidos anteriormente, os resultados mostram-se característicos de ambiente continental, com deposição em regiões isoladas, provavelmente do tipo lacustrino. Keith e Weber (1964) indicam valores semelhantes obtidos em conchas de pelecípodos e de gasterópodos recolhidos nos Grandes Lagos da América do Norte.

A grande e contínua variação encontrada em $\delta^{18} \mathrm{O}$ é também fator indicativo de um processo de forte evaporação a que a região esteve sujeita. Os baixos valores encontrados para $\delta^{18} \mathrm{O}$ podem sér explicados, segundo Epstein e Mayeda (1954), como resultante do fracionamento entre $\mathrm{H}_{2}{ }^{18} \mathrm{O}$ e $\mathrm{H}_{2}{ }^{16} \mathrm{O}$ durante um ciclo climático completo.

Como no caso dos dolomitos da unidade $\mathrm{A}$, esses valores constituem aqui também uma forte razão para admitir-se uma origem primária para os dolomitos.

CONCLUSÕES Os estudos até agora realizados sobre o Grupo Bambuí têm admitido um ambiente marinho para a sua formação. Com base nos resultados isotópicos àgora obtidos, é possível admitir-se que a região estudada teve uma evolução regular durante um período talassocrático, a qual poderá ser resumida conforme segue.

1) Formam-se pequenas bacias lacustres, sobre a Formação Bebedouro, (metassiltitos, ardósias e conglomerados) e depositam-se em ambiente continental os calcários dolomíticos e dolomitos argilosos da unidade C. A íntima associação dos carbonatos com material argiloso, bem como a coloração avermelhada característica e a ocorrência descontínua de rochas semelhantes na mesma posição estratigráfica verificada fora da área estudada, reforçam essa possibilidade. A presença de gretas de contração sugere a existência de longos períodos de exposição aérea durante a sedimentação.

2) A seguir, aparecem ambientes mistos, de alternância entre marinho restrito e continental, como parece ser evidenciado pela sedimentação da unidade $B$, que se processou como resultado de invasão marinha epicontinental. $O$ meio marinho restrito foi sempre caracterizado por uma fina lâmina de água e a região esteve sujeita a pequenas e constantes variações do nível do mar, permitindo que extensas áreas permanecessem periodicamente emersas e submersas. O caráter laminado da sedimentação, com alternância entre leitos carbonáticos e leitos síltico-argilosos, constitui evidência que sustenta os dados isotópicos obtidos.

3) Ao término do período ocorrem condições de sedimentação tipicamente marinhas (unidade A). Primeiro, com a deposição dos dolomitos da base, verificam-se condições bastante semelhantes às da unidade $\mathrm{B}$; ali, a razão alimentação/evaporação era muito baixa, o que ocasionou um forte fracionamento isotópico do oxigênio. Em seguida, o ambiente foi se tornando progressivamente mais marinho até chegar a um ponto, no final da deposição da seqüência carbonática, em que passou a ser francamente marinho.

Agradecimentos Os autores desejam agradecer aos colegas Robert Sweeney e Ilson Guimarães Carvalho, os quais participaram ativamente da fase inicial de planejamento deste trabalho. O Prof. Sweeney contribuiu, também, com oportunas sugestões, a partir dos primeiros resultados obtidos.

\section{BIBLIOGRAFIA}

AMARAL, G. e KAWASHITA, K. - 1967 - Determinação da idade do Grupo Bambuí pelo método Rb/Sr. An. XXI Congr. Bras. Geol. pp. 214-217. Curitiba, PR 
GLOUD, P. E. e DARDENNE, M. - 1973 - Proterozic age of the Bambui Group in Brazil. Geol. Soc. Amer. Bull, 84(5): 1673-1 676

CRAIG, H. - 1953 - The geochemistry of stable carbon isotopes. Geoch. Cosmoch. Acta, 3(2/3): $53-92$

GRAIG, H. - 1957 - Isotopic standards for carbon and oxygen and correction factors for mass spectrometric analysis of carbon dioxide. Geoch. Cosmoch. Acta, 12: 133-149

DEGENS, E. T. e EPSTEIN, S. - 1964 - Oxygen and carbon isotope ratios in coexisting calcites and dolomites from recent and ancient sediments. Geoch. Cosmoch. Acta, 28(1): 23-24

EPSTEIN, S. e MAYEDA, T. - 1954 - Variation of $\delta^{18} \mathrm{O}$ content of water from natural sources. Geoch. Cosmoch. Acta, 4(5): 213

FRITZ, P. - 1969 - The oxygen and carbon isotopic composition of carbonates from the Pine Point Lead-Zinc ore deposit. Econ. Geol. 64(7): 733-742

FRITZ, P., BINDA, P. L., FOLINSBEE, R. E. e KROUSE, H. R. - 1971 - Isotopic composition of diagenetic siderites from cretaceous sediments in Western Canada. Jour. Sed. Petrol. 41(1): 282-288

GALIMOV, E. M. - 1969 - Isotopic composition of carbon in gases of the crust. Intern. Geol. Rev., 11: $1092-1104$

GALIMOV, E. M. e GIRIN, Yu. P. - 1968 - Variation in the isotopic composition of carbon during the formation of carbonate concretions. Geochem. Inter., 5: 178-182

KEITH, M. L. e WEBER, J. N. - 1964 - Carbon and oxygen isotopic composition of selected limestones and fossils. Geoch. Gosmoch. Acta, 28(11): $1787-1816$

LAND, L. S. e EPSTEIN, S. - 1970 - Late pleistocene diagenesis and dolomitization, North Jamaica. Sedimentology, 14: 187-200

McCREA, J. M. - 1950 - On the isotopic chemistry of carbonates and a paleotemperature scale. J. Ghem. Phys. 18: 849-857

MISI, A. - 1973 - As mineralizações de chumbo, zinco, flúor e bário do Vale do Rio Jacaré (BA) e seu contex to geológico. Tese apresentada à UFBa para concurso de professor assistente

OANA, S. e DEEVEY, E. S. - 1960 - Carbon 13 in lake waters, and its possible bearing on paleolymnology. Amer. Journ. Scienc. 5 (258-A): 253-272

SCHIDLOWSKI, M., EICHMANN, R. e JUNGE, C. E. - 1975 - Precambrian sedimentary carbonates: carbon and oxygen isotope geochemistry and implication for the terrestrial oxygen Budget. Precambrian Research, 2(2): 1-69

WEBER, J. N., WILLIAMS, E. G. e KEITH, M. L. - 1964 - Paleoenvironmental significance of carbon isotopic composition of siderite nodules in some shales of pennsylvanian age. Journ. Sed. Petrol. 34(4): 814-818

WEBER, J. N. - 1964 - Garbon isotope ratios in dolostones: some implications concerning the genesis of secondary and "primary" dolostones. Geoch. Cosmoch. Acta. 28(11): $1257-1265$ 